\title{
Uterine artery embolization, surgery and high intensity focused ultrasound in the treatment of uterine fibroids: a network meta-analysis
}

\author{
Haijun Gao ${ }^{1}$, Tianping $\mathrm{Li}^{2}$, Dianxun $\mathrm{Fu}^{3}$, Jun $\mathrm{Wei}^{4}$ \\ ${ }^{1}$ Department of Radiology, Tianjin First Central Hospital, Tianjin, China; ${ }^{2}$ General Department, Chongqing Health Center for Women and \\ Children, Chongqing, China; ${ }^{3}$ Department of Radiology, Tianjin Medical University General Hospital, Tianjin, China; ${ }^{4}$ Department of Ultrasound, \\ Chongqing Health Center for Women and Children, Chongqing, China
}

Correspondence to: Jun Wei. Department of Ultrasound, Chongqing Health Center for Women and Children, No. 120 Longshan Road, Chongqing 401147, China. Email: Junwei2001@126.com.

\begin{abstract}
Background: To systematic review the safety and effectiveness between uterine artery embolization (UAE), surgery and high intensity focused ultrasound (HIFU) in the treatment of uterine fibroids.

Methods: The PubMed, EMbase, The Cochrane Library, Web of Science, Wanfang Data, and CNKI were electronically searched to collect relevant studies on comparing the safety and effectiveness of UAE, surgery and HIFU in the treatment of uterine fibroids from January 2000 to August 2019. After two reviewers independently screened the literature, extracted the data and evaluated the risk of bias of included studies, network meta-analysis was performed by ADDIS 1.16.8 and Stata 14 software.

Results: A total of 11 studies (22 articles) involving 3,646 patients were included. Compared with surgery, UAE and HIFU patients had higher quality of life (1-year follow-up) improvement, and UAE was higher than HIFU. Network meta-analysis show that patients treated with HIFU had the lowest incidence of major complications within 1 year, followed by UAE, and the highest surgery. Patients treated with HIFU and UAE have shorter hospital stays and quicker recovery time than surgery. The rate of further intervention after surgery treatment might be lower than that of UAE and HIFU.

Conclusions: UAE has the highest quality of life improvement (1-year follow-up) for uterine fibroids. HIFU and UAE are safer with shorter hospital stays and quicker recovery time compared with surgery. However, both UAE and HIFU have the risks of re-treatment. However, limited by the number and quality of included studies, the above conclusions need to be verified through more high-quality studies.
\end{abstract}

Keywords: Uterine fibroids; uterine artery embolization (UAE); surgery; high intensity focused ultrasound (HIFU); network meta-analysis

Submitted Dec 03, 2020. Accepted for publication Apr 02, 2021.

doi: 10.21037/qims-20-1331

View this article at: http://dx.doi.org/10.21037/qims-20-1331

\section{Introduction}

Uterine fibroid is the most common benign tumor among women of childbearing age, which can cause symptoms such as severe menstrual bleeding and pelvic pain. And serious cases can lead to infertility and miscarriage (1). Currently, the treatment methods of uterine fibroid mainly include drug therapy, conventional surgery, uterine artery embolization (UAE) and the newly emerging high intensity focused ultrasound (HIFU) (2), of which the surgical therapy can be further divided into hysterectomy (HY) and myomectomy (MY) in accordance with factors such as the location and size of fibroids and the requirements for fertility preservation of patients. MY can control patient symptoms and improve fertility, but it has more 


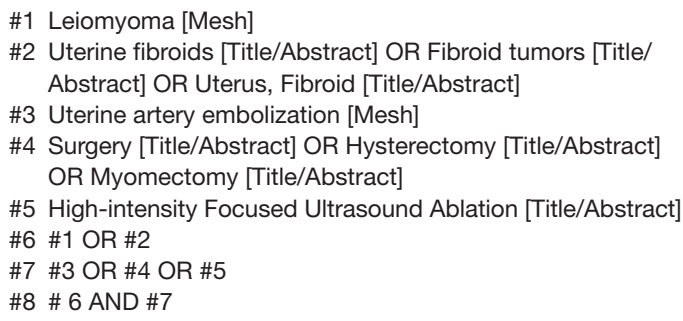

Figure 1 PubMed search strategy.

intraoperative blood loss and a higher incidence of abdominal adhesions (3). HY for uterine fibroids had a slower recovery time and more complications (4). Although UAE can significantly benefit patients, it has the risks of $\mathrm{X}$-ray exposure, puncture site hematoma, vascular wall thrombosis, pelvic ischemic pain, and uterine necrosis caused by excessive embolization $(5,6)$. HIFU is a relatively new treatment method for uterine fibroids, characterized by well therapeutic effect, rapid recovery, and fewer adverse effects. However, the reintervention rate of HIFU is higher than that of UAE (7). The current number of randomized controlled trials (RCTs) on the comparison of UAE, surgery and HIFU remains rather small with a limited sample size. The purpose of this study is to conduct a network metaanalysis comparing the safety and effectiveness of UAE, surgery and HIFU in the treatment of uterine fibroid.

\section{Methods}

\section{Inclusion criteria}

(I) RCTs and prospective cohort studies regardless of allocation concealment and blinding;

(II) Patients of childbearing age with uterine fibroids who experience symptoms including excessive menstrual bleeding and pelvic pain and have been clinically diagnosed through imaging methods such as ultrasound or magnetic resonance imaging (MRI), regardless of region and race;

(III) Intervention measures: UAE $v s$. surgery (HY or MY), surgery (HY or MY) vs. HIFU, UAE $v s$. HIFU, with UAE taking polyvinyl alcohol (PVA) (any diameter) as the embolic material.

\section{Exclusion criteria}

(I) Reviews, retrospective studies, conference abstracts and meta-analyses;

(II) Articles that fail to extract raw data for analysis;

(III) Articles with fewer than three outcome measures.

\section{Outcome measures}

The included articles should meet the following outcome measures of at least 3 items (including 3 items): (I) HealthRelated Quality of Life (HR-QOL): evaluating the quality of life of patients after treatment through instruments including but not limited to Uterine Fibroid Symptom and Quality of Life (UFS-QOL), SF-36 and EuroQOL-5D; (II) major complications: level C-F complications classified based on the criteria of Society of Interventional Radiology (SIR) (8) within 1 year after treatment; (III) minor complications: level A-B complications classified based on the criteria of SIR within 1 year after treatment; (IV) hospital stay; (V) recovery time; (VI) further intervention rate within 1 year after treatment. In the UAE arm, it included repeat UAE and therapeutic treatment (e.g., HIFU, HY, MY and endometrial ablation). In the HIFU arm, it included repeat HIFU and therapeutic treatment (e.g., UAE, HY, MY and endometrial ablation). In the surgery arm, it included repeat MY or HY, removal of cervical stump (following $\mathrm{HY}$ ) and endometrial ablation (following MY).

\section{Literature search strategy}

The combination of subject terms and free-text terms was mainly used to search the database. The English terms leiomyoma, uterine fibroid, surgery, hysterectomy, myomectomy, high-intensity focused ultrasound ablation, uterine artery embolization, prospective cohort study and RCT were searched in PubMed, Embase, The Cochrane Library (2020, Issue 8) and Web of Science. And the same terms in Chinese were searched in China National Knowledge Internet (CNKI) and Wanfang data with the date range set from January 2000 to August 2020. Search engines including Google Scholar and Baidu Wenku were also applied for manual searching of related literature. The reference lists of articles obtained were then retrieved and included as supplementary. Take PubMed as an example, Figure 1 indicates the specific search strategy.

\section{Literature selection and data extraction}

In accordance with the pre-determined inclusion and 
exclusion criteria, two reviewers (Dr. Tianping Li and Dr. Dianxun $\mathrm{Fu}$ ) read the titles and abstracts of the literature respectively and independently, excluded articles that failed to meet the criteria and conducted full text reading and data extraction on the ones that meet the criteria. Discussion was adopted in the case of disagreements and a third reviewer was introduced when necessary. Data extraction included: (I) general data: title, authors, published date; (II) basic features of the included literature: study subjects, age, interventions, number of cases, basic information of the patients (including age, mean maximum diameter and mean volume of the fibroids); (III) outcomes measures: HR-QOL, major complications [level C-F complications classified based on the criteria of SIR (8) within 1 year after treatment], minor complications (level A-B complications classified based on the criteria of SIR within 1 year after treatment), hospital stay, recovery time and further intervention rate within 1 year after treatment. For some studies that only provided medians, ranges or quartiles and could not be used and combined directly, to no avail in the case of contacting the authors for data, a validated method (9) was adopted to estimate its mean and standard deviation (SD).

\section{Risk-of-bias assessment of included studies}

The Cochrane risk-of-bias tool in the Cochrane Handbook for Systematic Reviews of Interventions 6.0 was used by two independent researchers for the assessment of RCTs. And the Newcastle-Ottawa Scale (NOS) was adopted for evaluating prospective cohort studies (10).

\section{Statistical analysis}

A network meta-analysis was performed by ADDIS1.16.8 Software. Binary variables took odds ratio (OR) and $95 \%$ CI whereas continuous variables took mean difference (MD) and $95 \% \mathrm{CI}$ as statistical indicators. Chi-squared tests were applied before combining the data for heterogeneity analysis. If $\mathrm{P}>0.01, \mathrm{I}^{2}<50 \%$, the heterogeneity level was low and a fixed-effects model was adopted for the network meta-analysis; whereas $\mathrm{P} \leq 0.01, \mathrm{I}^{2} \geq 50 \%$ indicated high level of heterogeneity. The sources of its heterogeneity were discussed and a random-effects model was then applied for the network meta-analysis when the sources could not be explained. A node-splitting model was used for inconsistency analysis. If there was no significant difference $(\mathrm{P}>0.05)$, a consistency model was adopted for the network meta-analysis and sequencing the results; if $\mathrm{P}<0.05$, an inconsistency model was then applied for the analysis of the sources of its inconsistency. The potential scale reduced factor (PSRF) was used to measure convergence. Good convergence was diagnosed when PSRF was close to or equaled to 1, indicating high reliability of the conclusions of the consistency model analysis. Lastly, the advantages and disadvantages of curative effects of each treatment method were estimated through sequencing the rates of outcomes (11).

\section{Results}

\section{Process and results of literature selection}

After initial search, 2,210 articles were collected and 11 studies [22 articles (12-33)] were finally included following the process of selection. Except for one prospective cohort study (15) and one comprehensive study (12-14,22) covering RCTs and prospective cohort study, nine other studies remained RCTs, which included one doctoral dissertation (28). Eleven studies were eligible for metaanalysis regarding the inclusion and exclusion criteria, in which a total of 3,646 patients were evaluated. The PRISMA flow diagram presents the search history in Figure 2.

\section{Basic features of included studies and results of risk-of-bias assessment}

See Table 1 for basic features of included studies and Table 2 for NOS scores of included prospective cohort studies. Table 3 summarizes the results of risk-of-bias assessment of RCTs.

\section{Results of HR-QOL analysis}

\section{UAE $v s$. surgery}

Both study Emmy [2005-2016] (16,18-20,30,31) and study Rest [2007-2013] $(17,26)$ adopted SF-36 and EuroQOL-5D for the evaluation of HR-QOL of patients. And there was no significant difference between UAE and surgery. UFSQOL was applied to assess the health condition of patients at 1 year after treatment in study Manyonda [2012] (23), suggesting that the improvement of health condition of patients in the UAE group was significantly greater than that of patients receiving surgical treatment based on the changes of indicators compared with the baseline $(\mathrm{P}<0.05)$. In study Jun [2012] (21), the results of SF-36 evaluation indicated that the improvement of physical function, social function, mental health, emotional function and 


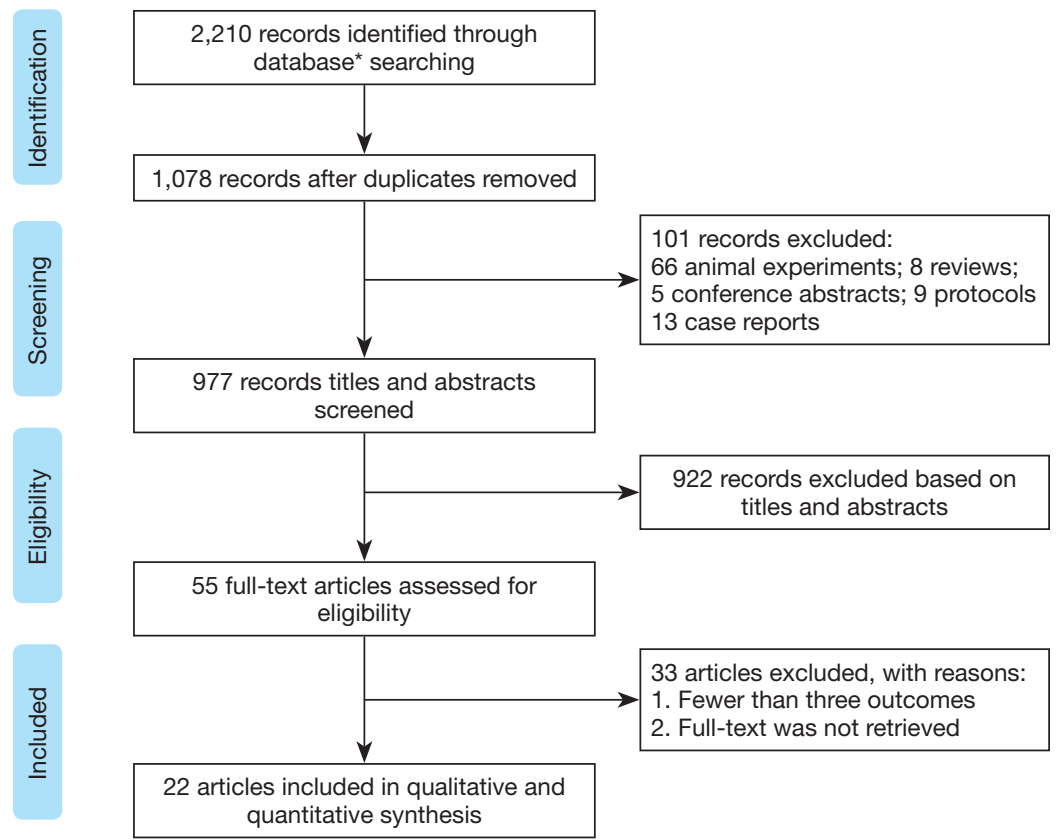

Figure 2 PRISMA flow diagram. *, PubMed (n=1,490), Embase ( $\mathrm{n}=441)$, Web of Science $(\mathrm{n}=226)$, The Cochrane Library (n=18), CNKI $(\mathrm{n}=20)$, Wanfang data $(\mathrm{n}=15)$.

Table 1 Basic features of included studies

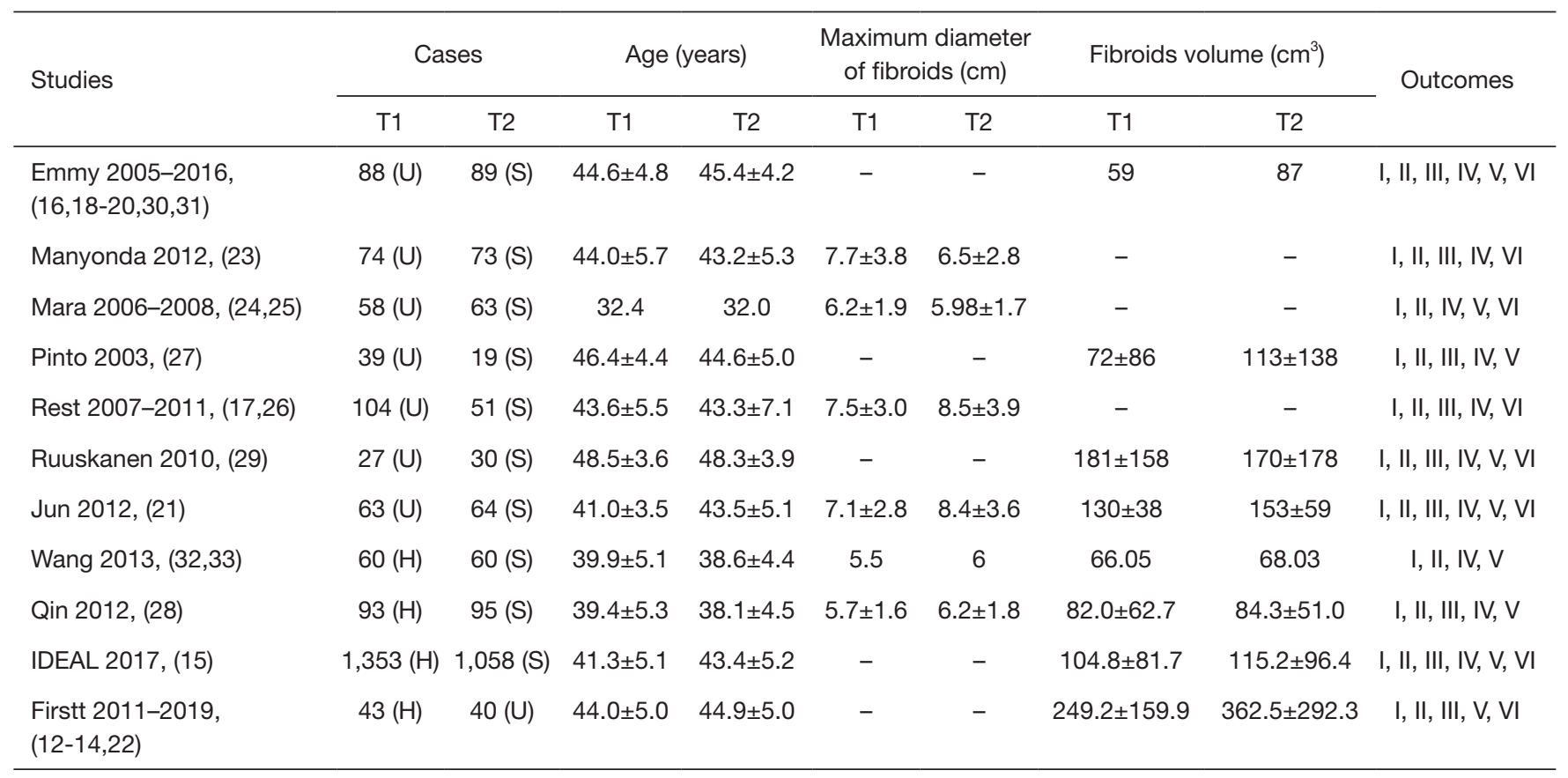

T1: treatment group; T2: control group; U: uterine artery embolization; S: surgery; H: high intensity focused ultrasound. I, Health-Related Quality of Life; II, major complications; III, minor complications; IV, hospital stay; V, recovery time; VI, further intervention rate within 1year after treatment. 
Table 2 NOS scores of included prospective cohort studies

\begin{tabular}{|c|c|c|c|c|c|c|c|c|c|}
\hline Studies & \multicolumn{4}{|c|}{ Selection } & $\frac{\text { Comparability }}{E}$ & \multicolumn{3}{|c|}{ Outcome } & Scores \\
\hline IDEAL 2017, (15) & 1 & 1 & 1 & 1 & 1 & 1 & 0 & 1 & 7 \\
\hline Firstt 2011-2019, (12-14,22) & 1 & 1 & 1 & 1 & 1 & 1 & 1 & 1 & 8 \\
\hline
\end{tabular}

A: representativeness of the exposed cohort; B: selection of the non-exposed cohort; C: ascertainment of exposure; D: demonstration that outcome of interest was not present at start of study; E: comparability of cohorts on the basis of the design or analysis; F: assessment of outcome; G: was follow-up long enough for outcomes to occur; H: adequacy of follow up of cohorts.

Table 3 Risk-of-bias assessment of RCTs

\begin{tabular}{|c|c|c|c|c|c|c|}
\hline Studies & $\begin{array}{c}\text { Random sequence } \\
\text { generation }\end{array}$ & $\begin{array}{c}\text { Allocation } \\
\text { concealment }\end{array}$ & $\begin{array}{l}\text { Binding of } \\
\text { allocated } \\
\text { intervention }\end{array}$ & $\begin{array}{l}\text { Incomplete outcome } \\
\text { data adequately } \\
\text { addressed }\end{array}$ & $\begin{array}{l}\text { Free of suggestion } \\
\text { selective outcome }\end{array}$ & $\begin{array}{c}\text { Other problems } \\
\text { with high risk of } \\
\text { bias }\end{array}$ \\
\hline Manyonda 2012, (23) & Low risk & Low risk & Unclear & ITT analysis & Low risk & Unclear \\
\hline Pinto 2003, (27) & Low risk & Low risk & Unclear & ITT analysis & Low risk & Unclear \\
\hline Rest 2007-2011, $(17,26)$ & Low risk & Unclear & Unclear & ITT analysis & Low risk & Unclear \\
\hline Ruuskanen 2010, (29) & Low risk & Low risk & Unclear & ITT analysis & Low risk & Unclear \\
\hline Jun 2012, (21) & Low risk & Unclear & Unclear & High risk & Low risk & Unclear \\
\hline $\begin{array}{l}\text { Firstt 2011-2019, } \\
(12-14,22)\end{array}$ & Low risk & Low risk & Low risk & ITT analysis & Low risk & Unclear \\
\hline
\end{tabular}

RCTs, randomized controlled trials; ITT, intention-to-treat.

energy levels of patients treated with UAE at 3 years after treatment was greater than that of patients in the surgery group, and the difference was statistically significant $(\mathrm{P}<0.05)$.

\section{Surgery $v s$. HIFU}

UFS-QOL and SF-36 were used in study IDEAL [2017] (15) for the assessment of HR-QOL of patients at 6 and 12 months after treatment. It was suggested in the UFSQOL results that the improvement of quality of life of patients receiving HIFU was greater than that of patients in the surgery group at 6 and 12 months after treatment, and the difference was statistically significant $(\mathrm{P}<0.05)$. And according to the results of SF-36, the improvement of physical function of patients in the HIFU group was significantly greater than that of patients underwent surgery at 6 and 12 months after treatment $(\mathrm{P}<0.05)$. No other significant difference was found between surgery and HIFU.

\section{UAE $v s$. HIFU}

In study Firstt [2011-2019] (12-14,22), UFS-QOL and SF-36 were applied to evaluate the HR-QOL of patients at 6,12 and 24 months after treatment. The results of UFS-QOL indicated that the improvement of quality of life of patients in the UAE group was significantly greater than that of patients receiving HIFU at 6, 12 and 24 months after treatment $(\mathrm{P}<0.05)$. And the results of SF-36 showed that the improvement of physical function and mental health of patients underwent UAE was greater than that of patients in the HIFU group at 12 months after treatment, and the difference was statistically significant $(\mathrm{P}<0.05)$. No other significant 
difference was found between UAE and HIFU.

\section{Results of a network meta-analysis}

A total of 11 studies were included: 14 articles (16-21,2327,29-31) on UAE $v s$. surgery (7 RCTs), 4 articles on surgery $v s$. HIFU $[2$ RCTs $(28,32,33)$ and 1 prospective cohort study (15)] and 4 articles $(12-14,22)$ on UAE $v s$. HIFU (1 comprehensive study including both RCTs and prospective cohort study). The total cases for UAE, surgery and HIFU were 498, 1,602 and 1,546 separately. Figure 3 demonstrated the direct comparison of three treatment methods.

\section{Major complications}

Major complications within 1 year after treatment were covered in 11 studies (12-33), and the total cases of major complications for UAE, surgery and HIFU were 29 (5.8\%), $186(11.6 \%), 6(0.4 \%)$. A low heterogeneity was revealed through heterogeneity analysis $\left(\mathrm{I}^{2}<50 \%\right)$. No significant difference was found in the inconsistency analysis by the

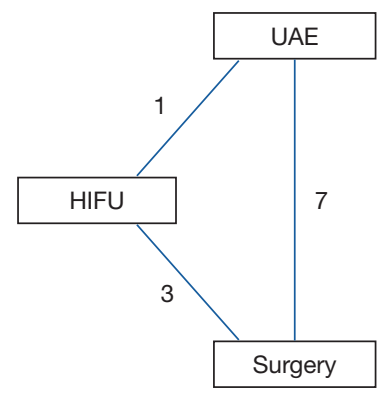

Figure 3 Direct comparison of three treatment methods. UAE, uterine artery embolization; HIFU, high intensity focused ultrasound. node-splitting model $(\mathrm{P}>0.05)$. It was indicated in the network meta-analysis by the consistency model that the incidence of major complications of patients in the UAE group $(\mathrm{OR}=0.33,95 \% \mathrm{CI}: 0.10,0.98, \mathrm{P}<0.05)$ and the HIFU group $(\mathrm{OR}=0.05,95 \% \mathrm{CI}: 0.01,0.23, \mathrm{P}<0.05)$ was lower than that of patients in the surgery group within 1 year after treatment, and the difference was statistically significant. The incidence of major complications of patients in the HIFU group (OR $=0.17,95 \%$ CI: $0.03,0.95, \mathrm{P}<0.05)$ was significantly lower than that of patients in the UAE group within 1 year after treatment (Table 4). The sequence of incidence rate of major complications within 1 year after treatment was as follows: surgery > UAE > HIFU (Figure 4).

\section{Minor complications}

Minor complications within 1 year after treatment were discussed in nine studies (12-23,26-31), and the total cases of minor complications for UAE, surgery and HIFU were 196 (39.4\%), 900 (56.2\%), 435 (28.1\%). The heterogeneity was shown in the UAE group and the surgery group through heterogeneity analysis $\left(\mathrm{P}=0.042, \mathrm{I}^{2}=56.5 \%\right)$. After excluding the study with high heterogeneity, i.e., Pinto [2003] (27), through sensitivity analysis, no heterogeneity was found $\left(\mathrm{P}=0.495, \mathrm{I}^{2}=0 \%\right)$. Significant difference was observed in the inconsistency analysis by the node-splitting model $(\mathrm{P}<0.05)$. It was demonstrated in the network metaanalysis by the consistency model that the incidence of minor complications of patients in the surgery group and the HIFU group could be lower than that of patients in the UAE group within 1 year after treatment, and the difference was not statistically significant. The incidence of minor complications of patients receiving HIFU was lower than that of patients underwent surgery within 1 year after treatment with no significant difference (Table 4). The inconsistency was due to the conflicts between

Table 4 Network meta-analysis results for different methods in the treatment of uterine fibroids

\begin{tabular}{|c|c|c|c|c|c|c|}
\hline Outcomes & \multicolumn{2}{|l|}{ UAE vs. surgery } & \multicolumn{2}{|c|}{ HIFU vs. surgery } & \multicolumn{2}{|c|}{ HIFU vs. UAE } \\
\hline Major complications & $0.33(0.10,0.98)$ & 0.028 & $0.05(0.01,0.23)$ & 0.001 & $0.17(0.03,0.95)$ & 0.022 \\
\hline Minor complications & $1.39(0.46,4.13)$ & 0.721 & $0.40(0.13,2.09)$ & 0.097 & $0.83(0.12,4.48)$ & 0.420 \\
\hline Hospital stay & $-3.31(-5.95,-0.85)$ & 0.005 & $-4.29(-6.84,-1.80)$ & 0.001 & $-1.70(-4.31,1.03)$ & 0.106 \\
\hline Further intervention rate & $4.51(1.61,13.90)$ & 0.076 & $16.27(2.91,112.05)$ & 0.274 & $3.58(0.64,21.53)$ & 0.736 \\
\hline
\end{tabular}

UAE, uterine artery embolization; OR, odds ratio; MD, mean difference; Cl, confidence interval; HIFU, high intensity focused ultrasound. 

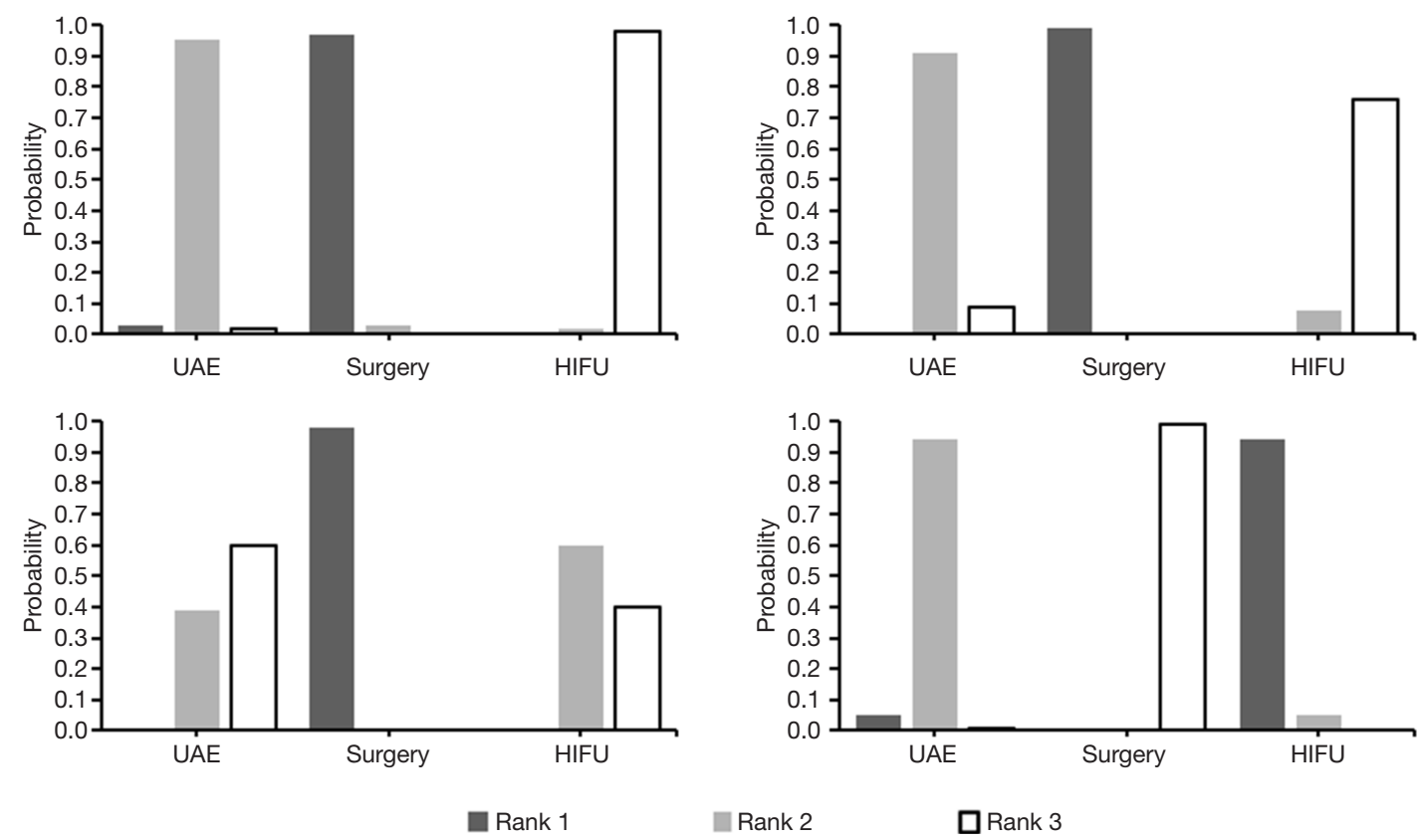

Figure 4 The sequence of treatment methods in different outcomes. (A) Major complications; (B) hospital stay; (C) recovery time; (D) further intervention rate after treatment. UAE, uterine artery embolization; HIFU, high intensity focused ultrasound.

indirect and direct comparison of results. According to study Firstt [2011-2019] (12-14,22), the incidence of minor complications of patients in the HIFU group $(\mathrm{OR}=1.91$, 95\% CI: $0.75,4.83, \mathrm{P}>0.05)$ could be higher than that of patients in the UAE group within 1 year after treatment, which was in conflict with the results of the network metaanalysis. Thus, it could not be concluded that there was difference among the three treatment methods.

\section{Hospital stay}

The hospital stay was mentioned in 10 studies $(13,16-21$, 23-33), and the average hospital stay for UAE, surgery and HIFU were $2.22 \pm 1.31,5.77 \pm 2.13$ and $1.22 \pm 1.59$ days. A high heterogeneity was observed in the UAE group and the surgery group through heterogeneity analysis $(\mathrm{P}<0.001$, $\left.\mathrm{I}^{2}=86 \%\right)$. After excluding two studies with high heterogeneity, i.e., Ruuskanen [2010] (29) and Mara [2006-2008] (24,25), through sensitivity analysis, no heterogeneity was found $\left(\mathrm{P}=0.46, \mathrm{I}^{2}=0 \%\right)$. It was indicated in the network metaanalysis by the consistency model that the hospital stay of patients in the UAE group and the HIFU group was shorter than that of patients underwent surgical treatment $(\mathrm{P}<0.05)$, of which patients receiving HIFU had the shortest hospitalization time with no significant difference (Table 4). The sequence of hospital stay of patients was as follows: surgery > UAE > HIFU (Figure 4).

\section{Recovery time}

The recovery time of patients was discussed in nine studies $(15,16,18-21,24,25,27-33)$, and the average recovery time for UAE, surgery and HIFU were $8.11 \pm 4.89,27.42 \pm 15.43$ and $10.12 \pm 6.39$ days. A high heterogeneity was revealed in the UAE group and the surgery group through heterogeneity analysis $\left(\mathrm{P}<0.001, \mathrm{I}^{2}=86 \%\right)$. After excluding three studies with high heterogeneity, i.e., Emmy [20052016] (16,18-20,30,31), Mara [2006-2008] (24,25) and Jun [2012] (21), through sensitivity analysis, no heterogeneity was found $\left(\mathrm{P}>0.5, \mathrm{I}^{2}=0\right)$. No significant difference was observed in the inconsistency analysis by the node-splitting model $(\mathrm{P}>0.05)$. It was suggested in the network metaanalysis by the consistency model that the recovery time of patients in the UAE group and the HIFU group was shorter than that of patients underwent surgical treatment $(\mathrm{P}<0.05)$, of which patients receiving UAE had the shortest recovery time with no significant difference (Table 4). The sequence of recovery time of patients was as follows: surgery $>$ HIFU $>\operatorname{UAE}$ (Figure 4).

\section{Further intervention rate after treatment}

The further intervention rate within 1 year after treatment 


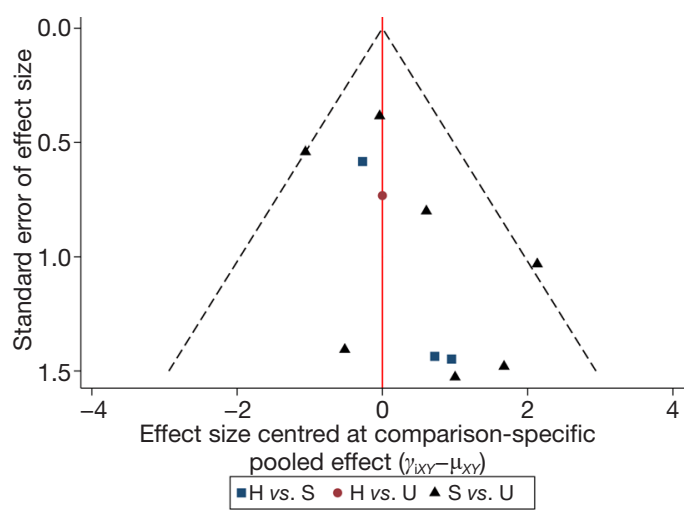

Figure 5 Funnel plots of objective cure rate with 11 RCTs. U: uterine artery embolization; S: surgery; $\mathrm{H}$ : high intensity focused ultrasound. RCTs, randomized controlled trials.

was mentioned in eight studies (12-26,29-31), and the total cases of further interventions for UAE, surgery and HIFU were 111 (22.3\%), 30 (18.7\%), 27 (17.5\%). A high heterogeneity was observed in the UAE group and the surgery group through heterogeneity analysis $\left(\mathrm{P}=0.068, \mathrm{I}^{2}=51.2 \%\right)$. After excluding two studies with high heterogeneity, i.e., Jun [2012] (21) and Mara [2006-2008] $(24,25)$, through sensitivity analysis, no heterogeneity was found $\left(\mathrm{P}>0.5, \mathrm{I}^{2}=0\right)$. No significant difference was shown in the inconsistency analysis by the node-splitting model $(\mathrm{P}>0.05)$. It was indicated in the network meta-analysis by the consistency model that the further intervention rate after treatment of patients in the UAE group and the HIFU group was higher than that of patients underwent surgical treatment $(\mathrm{P}<0.05)$, of which patients receiving HIFU had the highest further intervention rate after treatment with no significant difference (Table 4). The sequence of further intervention rate after treatment was as follows: HIFU > UAE > surgery (Figure 4).

\section{Publication bias analysis}

Publication bias analysis was conducted on the outcome of major complications. The funnel plot (Figure 5) appears to be asymmetrical with the included articles mostly plotted to the right side of the midline, indicating the possibilities of publication bias or effects of small sample size.

\section{Discussion}

Currently, the increasing treatment methods of uterine fibroid mainly include surgical treatment and nonsurgical treatment (e.g., UAE and HIFU). According to this study, UFS-QOL was applied to evaluate the HRQOL of patients at 1 year after treatment in the followup. It was revealed in the direct pairwise comparison that patients receiving UAE and HIFU had higher quality of life after treatment compared with that of patients underwent surgery, of which patients treated with UAE had the highest HR-QOL. The network meta-analysis suggested that HIFU had the lowest incidence of major complications within 1 year after treatment, followed by $\mathrm{UAE}$, whereas that of surgery remained the highest in the treatment of uterine fibroid. No significant difference was observed in the incidence of minor complications within 1 year after treatment among the three treatment methods. The hospital stay and recovery time of patients treated with HIFU and UAE remained relatively shorter, and the further intervention rate of HIFU was higher than that of UAE and surgical treatment.

Thus, the three treatment methods of uterine fibroid have different characteristics. Among the common surgical treatments, HY remains the only treatment method that can effectively reduce the recurrence of uterine fibroid for patients without requirements for fertility preservation (34), of which laparoscopic HY is featured by minor invasion and rapid recovery with proficiency requirements of the operator and relatively high cost. Whereas MY is the main choice for patients with requirements for fertility preservation or of childbearing age, of which transvaginal MY has been adopted increasingly due to its simplicity in operation and minor invasion. Although the limited data of HIFU and UAE do not show that they have adverse effects on pregnancy outcomes, HIFU and UAE are not recommended for patients with requirements for fertility preservation due to lack of large-scale prospective clinical trials. However, the curative effects of transvaginal MY on relatively larger fibroids are often unsatisfactory under the restriction of size and number of fibroids (35).

Super-selective UAE is performed based on the blood supply of uterine fibroids to cause ischemia and necrosis in order to achieve therapeutic purpose. Hence, UAE is suitable for rich blood supply fibroids. Li et al. (36) demonstrated that the volume of fibroids with rich blood supply begins to shrink in one week after UAE, while the volume of fibroids with insufficient blood supply begins to shrink in 1 month after UAE. This treatment method is characterized by simplicity in operation, minor invasion compared with surgery, short recovery time and no 
limitation on size and number of fibroids. It is considered conventionally that fertility preservation remains a relative contraindication for UAE, however, according to a study (37), the pregnancy rate of patients underwent UAE can reach $59.5 \%$, suggesting that UAE is safe for patients with requirements for fertility preservation. Another study (38) demonstrates that the curative effects of UAE are also satisfactory on uterine fibroids greater than 10 $\mathrm{cm}$ in diameter. Due to the risks of misembolization and embolization syndrome, some patients experience ovarian artery misembolization that damages ovarian function and manifestation of the embolization syndrome including pain, vomiting and fever after treatment. And there are cases where UAE leads to severe complications or even death (39).

As a non-invasive treatment, HIFU accurately locates target issue under the guidance of MRI or ultrasound, generates high energy to target and penetrate body tissues, and ablates the fibroids to achieve curative effects. Mindjuk et al. (40) reported that the efficacy of HIFU in the treatment of uterine fibroids was significantly positively correlated with the percentage of non-perfused volume (NPV\%), and the recurrence rate was significantly reduced when the NPV\% was $>80 \%$. According to Funaki classification scheme (41), Funaki type III uterine fibroids are rich in arterial blood supply. Due to the rich arterial blood supply, the blood flow will take away part of the energy during treatment, which is not conducive to ultrasound energy aggregation and affects the therapeutic effect. Hence, Funaki type III uterine fibroids are not suitable for HIFU treatment. The treatment method features short recovery time, low occurrence of severe complications (42) and relatively minor pain after treatment compared with UAE. It is suggested in a study (43) of 3 years follow-up of 43 patients with uterine fibroid that no recurrence occurs and HIFU proves to be a feasible, safe and effective treatment method. A comparative study (44) showed that the pregnancy rates in the HIFU group (68.4\%) were similar to that in the MY group $(66.7 \%)$, and the average time to pregnancy was shorter in the HIFU group. Qu et al. (45) indicated that HIFU in the treatment of uterine fibroids did not influence ovarian function. However, its further intervention rate increases affected by the size and location of fibroids (46). Besides, minor complications such as abdominal pain, skin ulcers of treated areas and hematuria may develop after the treatment of HIFU, which is still worth noticing despite its low occurrence. HIFU is a relatively new treatment method, and still has limitations.
It is believed that with the improvement and development of technology, HIFU will certainly become the mainstream modality for the treatment of uterine fibroids and result in better treatment results in future.

Limitations of the present study are as follows: (I) the location and number of uterine fibroids are not mentioned in the included studies, hence their influence on the three treatment methods remains uncertain. (II) The surgical methods included in the surgery group vary as a subgroup analysis of $\mathrm{HY}$ and MY with separate data is not conducted, which may result in the increase of heterogeneity and cause bias. (III) Different evaluation methods assessing the quality of life of patients are applied in the included studies with different follow-up time, which fails to generate appropriate data for a network meta-analysis. As a result, only a pairwise comparison based on one evaluation method with a 1-year follow-up time is conducted. (IV) The inclusion and exclusion criteria are not strictly developed for patients of the included studies, so patient inclusion and exclusion criteria are not similar between the included studies. Therefore, the results and conclusion should be used with caution.

To sum up, HIFU and UAE have the advantages of higher quality of life, lower occurrence of major complications, shorter hospital stay and recovery time, etc. in the treatment of uterine fibroid compared with surgery, of which patients underwent UAE have slightly higher quality of life than that of HIFU patients. No difference of minor complications is observed among the three treatment methods. The occurrence of further intervention of surgical treatment remains lower than that of HIFU and UAE. Therefore, a suitable treatment method should be selected according to the specific conditions of patients with uterine fibroid in clinical practice. More multicenter RCTs with higher quality and larger sample should be conducted in the future to further benefit the comprehensive evaluation of the safety and effectiveness of the treatment methods of uterine fibroid.

\section{Acknowledgments}

Funding: None.

\section{Footnote}

Conflicts of Interest: All authors have completed the ICMJE uniform disclosure form (available at http://dx.doi. 
org/10.21037/qims-20-1331). The authors have no conflicts of interest to declare.

Ethical Statement: The authors are accountable for all aspects of the work in ensuring that questions related to the accuracy or integrity of any part of the work are appropriately investigated and resolved.

Open Access Statement: This is an Open Access article distributed in accordance with the Creative Commons Attribution-NonCommercial-NoDerivs 4.0 International License (CC BY-NC-ND 4.0), which permits the noncommercial replication and distribution of the article with the strict proviso that no changes or edits are made and the original work is properly cited (including links to both the formal publication through the relevant DOI and the license). See: https://creativecommons.org/licenses/by-nc-nd/4.0/.

\section{References}

1. Hartmann KE, Birnbaum H, Ben-Hamadi R, Wu EQ, Farrell MH, Spalding J, Stang P. Annual costs associated with diagnosis of uterine leiomyomata. Obstet Gynecol 2006;108:930-7.

2. Donnez J, Dolmans MM. Uterine fibroid management: from the present to the future. Hum Reprod Update 2016;22:665-86.

3. Thompson LB, Reed SD, McCrummen BK, Warolin AK, Newton KM. Leiomyoma characteristics and risk of subsequent surgery after myomectomy. Int J Gynaecol Obstet 2006;95:138-43.

4. Dedden SJ, Geomini P, Huirne JAF, Bongers MY. Vaginal and Laparoscopic hysterectomy as an outpatient procedure: A systematic review. Eur J Obstet Gynecol Reprod Biol 2017;216:212-23.

5. Kohi MP, Spies JB. Updates on Uterine Artery Embolization. Semin Intervent Radiol 2018;35:48-55.

6. de Bruijn AM, Adriaansens SJH, Smink M, Venmans A, Hehenkamp WJK, Smeets AJ, Lopez A, Huirne JAF, Lohle PNM. Uterine Artery Embolization in Women with Symptomatic Cervical Leiomyomata: Efficacy and Safety. Cardiovasc Intervent Radiol 2019;42:371-80.

7. Gizzo S, Saccardi C, Patrelli TS, Ancona E, Noventa M, Fagherazzi S, Mozzanega B, D'Antona D, Nardelli GB. Magnetic resonance-guided focused ultrasound myomectomy: safety, efficacy, subsequent fertility and quality-of-life improvements, a systematic review. Reprod Sci 2014;21:465-76.
8. Spies JB, Spector A, Roth AR, Baker CM, Mauro L, Murphy-Skrynarz K. Complications after uterine artery embolization for leiomyomas. Obstet Gynecol 2002;100:873-80.

9. Hozo SP, Djulbegovic B, Hozo I. Estimating the mean and variance from the median, range, and the size of a sample. BMC Med Res Methodol 2005;5:13.

10. Wells GA, Shea B, O'Connell D, Peterson J, Welch V, Losos M, Tugwell P. The Newcastle-Ottawa Scale (NOS) for Assessing the Quality of Non-Randomized Studies in Meta-Analysis. Applied Engineering in Agriculture 2014;18:727-34.

11. Zeng XT, Zhang C, Du L. Using ADDIS software for implementation network meta-analysis. Chin J Evid-Based Med 2013;13:1508-15.

12. AbdElmagied AM, Vaughan LE, Weaver AL, LaughlinTommaso SK, Hesley GK, Woodrum DA, Jacoby VL, Kohi MP, Price TM, Nieves A, Miller MJ, Borah BJ, Gorny KR, Leppert PC, Lemens MA, Stewart EA. Fibroid interventions: reducing symptoms today and tomorrow: extending generalizability by using a comprehensive cohort design with a randomized controlled trial. Am J Obstet Gynecol 2016;215:338.e1-338.e18.

13. Barnard EP, AbdElmagied AM, Vaughan LE, Weaver AL, Laughlin-Tommaso SK, Hesley GK, Woodrum DA, Jacoby VL, Kohi MP, Price TM, Nieves A, Miller MJ, Borah BJ, Gorny KR, Leppert PC, Peterson LG, Stewart EA. Periprocedural outcomes comparing fibroid embolization and focused ultrasound: a randomized controlled trial and comprehensive cohort analysis. Am J Obstet Gynecol 2017;216:500.e1-500.e11.

14. Bouwsma EV, Hesley GK, Woodrum DA, Weaver AL, Leppert PC, Peterson LG, Stewart EA. Comparing focused ultrasound and uterine artery embolization for uterine fibroids-rationale and design of the Fibroid Interventions: reducing symptoms today and tomorrow (FIRSTT) trial. Fertil Steril 2011;96:704-10.

15. Chen J, Li Y, Wang Z, McCulloch P, Hu L, Chen W, Liu G, Li J, Lang J; Committee of the Clinical Trial of HIFU versus Surgical Treatment for Fibroids. Evaluation of high-intensity focused ultrasound ablation for uterine fibroids: an IDEAL prospective exploration study. BJOG 2018 Feb;125:354-64.

16. de Bruijn AM, Ankum WM, Reekers JA, Birnie E, van der Kooij SM, Volkers NA, Hehenkamp WJ. Uterine artery embolization vs hysterectomy in the treatment of symptomatic uterine fibroids: 10 -year outcomes from the randomized EMMY trial. Am J Obstet Gynecol 
2016;215:745.e1-745.e12.

17. Edwards RD, Moss JG, Lumsden MA, Wu O, Murray LS, Twaddle S, Murray GD. Uterine-artery embolization versus surgery for symptomatic uterine fibroids. N Engl J Med 2007;356:360-70.

18. Hehenkamp WJ, Volkers NA, Birnie E, Reekers JA, Ankum WM. Pain and return to daily activities after uterine artery embolization and hysterectomy in the treatment of symptomatic uterine fibroids: results from the randomized EMMY trial. Cardiovasc Intervent Radiol 2006;29:179-87.

19. Hehenkamp WJ, Volkers NA, Birnie E, Reekers JA, Ankum WM. Symptomatic uterine fibroids: treatment with uterine artery embolization or hysterectomy-results from the randomized clinical Embolisation versus Hysterectomy (EMMY) Trial. Radiology 2008;246:823-32.

20. Hehenkamp WJ, Volkers NA, Donderwinkel PF, de Blok S, Birnie E, Ankum WM, Reekers JA. Uterine artery embolization versus hysterectomy in the treatment of symptomatic uterine fibroids (EMMY trial): peri- and postprocedural results from a randomized controlled trial. Am J Obstet Gynecol 2005;193:1618-29.

21. Jun F, Yamin L, Xinli X, Zhe L, Min Z, Bo Z, Wenli G. Uterine artery embolization versus surgery for symptomatic uterine fibroids: a randomized controlled trial and a meta-analysis of the literature. Arch Gynecol Obstet 2012;285:1407-13.

22. Laughlin-Tommaso S, Barnard EP, AbdElmagied AM, Vaughan LE, Weaver AL, Hesley GK, Woodrum DA, Jacoby VL, Kohi MP, Price TM, Nieves A, Miller MJ, Borah BJ, Moriarty JP, Gorny KR, Leppert PC, Severson AL, Lemens MA, Stewart EA. FIRSTT study: randomized controlled trial of uterine artery embolization vs focused ultrasound surgery. Am J Obstet Gynecol 2019;220:174. e1-174.e13.

23. Manyonda IT, Bratby M, Horst JS, Banu N, Gorti M, Belli AM. Uterine artery embolization versus myomectomy: impact on quality of life--results of the FUME (Fibroids of the Uterus: Myomectomy versus Embolization) Trial. Cardiovasc Intervent Radiol 2012;35:530-6.

24. Mara M, Fucikova Z, Maskova J, Kuzel D, Haakova L. Uterine fibroid embolization versus myomectomy in women wishing to preserve fertility: preliminary results of a randomized controlled trial. Eur J Obstet Gynecol Reprod Biol 2006;126:226-33.

25. Mara M, Maskova J, Fucikova Z, Kuzel D, Belsan T, Sosna O. Midterm clinical and first reproductive results of a randomized controlled trial comparing uterine fibroid embolization and myomectomy. Cardiovasc Intervent Radiol 2008;31:73-85.

26. Moss JG, Cooper KG, Khaund A, Murray LS, Murray GD, Wu O, Craig LE, Lumsden MA. Randomised comparison of uterine artery embolisation (UAE) with surgical treatment in patients with symptomatic uterine fibroids (REST trial): 5-year results. BJOG 2011;118:936-44.

27. Pinto I, Chimeno P, Romo A, Paul L, Haya J, de la Cal MA, Bajo J. Uterine fibroids: uterine artery embolization versus abdominal hysterectomy for treatment--a prospective, randomized, and controlled clinical trial. Radiology 2003;226:425-31.

28. Qin J. Safety of trauma and local tumor effect after highintensity focused ultrasound ablation of uterine fibroid [doctoral]. Chongqing Medical University, 2012.

29. Ruuskanen A, Hippelainen M, Sipola P, Manninen H. Uterine artery embolisation versus hysterectomy for leiomyomas: primary and 2-year follow-up results of a randomised prospective clinical trial. Eur Radiol 2010;20:2524-32.

30. van der Kooij SM, Hehenkamp WJ, Volkers NA, Birnie E, Ankum WM, Reekers JA. Uterine artery embolization vs hysterectomy in the treatment of symptomatic uterine fibroids: 5-year outcome from the randomized EMMY trial. Am J Obstet Gynecol 2010;203:105.e1-13.

31. Volkers NA, Hehenkamp WJ, Birnie E, Ankum WM, Reekers JA. Uterine artery embolization versus hysterectomy in the treatment of symptomatic uterine fibroids: 2 years' outcome from the randomized EMMY trial. Am J Obstet Gynecol 2007;196:519.e1-11.

32. Wang X, Qin J, Chen J, Wang L, Chen W, Tang L. The effect of high-intensity focused ultrasound treatment on immune function in patients with uterine fibroids. Int $\mathrm{J}$ Hyperthermia 2013;29:225-33.

33. Wang X, Qin J, Wang L, Chen J, Chen W, Tang L. Effect of high-intensity focused ultrasound on sexual function in the treatment of uterine fibroids: comparison to conventional myomectomy. Arch Gynecol Obstet 2013;288:851-8.

34. Thubert T, Foulot H, Vinchant M, Santulli P, Marzouk P, Borghese B, Chapron C. Surgical treatment: Myomectomy and hysterectomy; Endoscopy: A major advancement. Best Pract Res Clin Obstet Gynaecol 2016;34:104-21.

35. Chen CL, Liu P, Zeng BL, Ma B, Zhang H. Intermediate and long term clinical effects of uterine arterial embolization in treatment of adenomyosis. Zhonghua Fu Chan Ke Za Zhi 2006 Oct;41:660-3.

36. Li Z, Wang YL, Dong G, Li LJ, Chen YC, Hua SH. The 
application of contrast-enhanced ultrasound in evaluating the curative effect of uterine artery embolization for fibroids. Journal of Interventional Radiology 2019;28:842-6.

37. Pisco JM, Duarte M, Bilhim T, Cirurgiao F, Oliveira AG. Pregnancy after uterine fibroid embolization. Fertil Steril 2011;95:1121.e5-8.

38. Bérczi V, Valcseva É, Kozics D, Kalina I, Kaposi P, Sziller P, Várbíró S, Botos EM. Safety and Effectiveness of UFE in Fibroids Larger than $10 \mathrm{~cm}$. Cardiovasc Intervent Radiol 2015;38:1152-6.

39. Fennessy FM, Kong CY, Tempany CM, Swan JS. Qualityof-life assessment of fibroid treatment options and outcomes. Radiology 2011;259:785-92.

40. Mindjuk I, Trumm CG, Herzog P, Stahl R, Matzko M. MRI predictors of clinical success in MR-guided focused ultrasound (MRgFUS) treatments of uterine fibroids: results from a single centre. Eur Radiol 2015;25:1317-28.

41. Funaki K, Fukunishi H, Funaki T, Sawada K, Kaji Y, Maruo T. Magnetic resonance-guided focused ultrasound surgery for uterine fibroids: relationship between the therapeutic effects and signal intensity of preexisting T2-weighted magnetic resonance images. Am J Obstet Gynecol 2007;196:184.e1-6.

Cite this article as: Gao H, Li T, Fu D, Wei J. Uterine artery embolization, surgery and high intensity focused ultrasound in the treatment of uterine fibroids: a network meta-analysis. Quant Imaging Med Surg 2021;11(9):4125-4136. doi: 10.21037/ qims-20-1331
42. Skehan SJ, Malone DE, Buckley N, Matsumoto S, Rawlinson J, Ting G, Graham D, Alexander J, Somers S, Stevenson GW. Sedation and analgesia in adult patients: evaluation of a staged-dose system based on body weight for use in abdominal interventional radiology. Radiology 2000;216:653-9.

43. Xu YH, Chen WZ. Complete ablation of uterine fibroids by MR-guided high intensity focused ultrasound: feasibility, safety and long- term outcome. Journal of Interventional Radiology 2014;23:959-68.

44. Wu G, Li R, He M, Pu Y, Wang J, Chen J, Qi H. A comparison of the pregnancy outcomes between ultrasound-guided high- intensity focused ultrasound ablation and laparoscopic myomectomy for uterine fibroids: a comparative study. Int J Hyperthermia 2020;37:617-23.

45. Qu K, Mao S, Li J, Wang J, Ouyang G, Wang Z, Wang Z, Xiong Y, Zhang L. The impact of ultrasound-guided highintensity focused ultrasound for uterine fibroids on ovarian reserve. Int J Hyperthermia 2020;37:399-403.

46. Fennessy FM, Tempany CM, McDannold NJ, So MJ, Hesley G, Gostout B, Kim HS, Holland GA, Sarti DA, Hynynen K, Jolesz FA, Stewart EA. Uterine leiomyomas: MR imaging-guided focused ultrasound surgery--results of different treatment protocols. Radiology 2007;243:885-93. 